\title{
A escuta do sofrimento psíquico relacionado ao trabalho: contribuições da psicanálise para o cuidado em saúde
}

Listening to the work-related suffering: contributions of psychoanalysis on health care

La escucha del sufrimiento psíquico relacionado con el trabajo: contribuciones del psicoanálisis al cuidado en la salud

\author{
Lia Carneiro Silveira* \\ Rúbia Mara Maia Feitosa ${ }^{* *}$ \\ Paula Danyelle Barros Palácio ${ }^{* * *}$
}

\begin{abstract}
Resumo
Objetivamos, com base em um caso clínico, exemplificar como a escuta de uma queixa relacionada ao trabalho pode ser apreendida na perspectiva da singularidade do sujeito e refletir acerca da contribuição dessa escuta para a atenção à saúde do trabalhador. Pauta-se em uma pesquisa desenvolvida por meio do método de estudo de caso em psicanálise. Discutiu-se como a queixa relacionada ao trabalho pôde ser abordada com base na singularidade do sujeito. No estudo, conclui-se que, ao nos debruçarmos sobre a questão do sofrimento psíquico do trabalhador sob uma ótica psicanalítica, podemos ir além da abordagem da queixa com base no modelo médico de atenção à saúde, articulando esse sofrimento às séries psíquicas que marcam a estruturação desse sujeito.
\end{abstract}

Palavras-chave: Sofrimento psíquico. Psicanálise. Saúde do trabalhador.

\begin{abstract}
We aimed to exemplify, from a clinical case, how listening to a complaint related to work can be understood in a perspective of the singularity of the subject and reflect on the contributions of this listening for the worker's health care. The study was based on a survey conducted by the method of case study in psychoanalysis. We discussed how the complaint related to work could be approached from the singularity of the
\end{abstract}

\footnotetext{
Docente do Programa de Pós-graduação Cuidados Clínicos em Enfermagem e Saúde da Universidade Estadual do Ceará (Ppcclis/UECE); psicanalista do Fórum do Campo Lacaniano em Fortaleza-CE; enfermeira. E-mail: silveiralia@gmail. com.

** Mestranda do Programa de Pós-graduação Cuidados Clínicos em Enfermagem e Saúde da Universidade Estadual do Ceará (Ppcclis/UECE); bolsista da Fundação Cearense de Apoio ao Desenvolvimento Científico e Tecnológico (Funcap); enfermeira. E-mail: rubinhafeitosa@hotmail.com.

*** Mestranda do Programa de Pós-graduação Cuidados Clínicos em Enfermagem e Saúde da Universidade Estadual do Ceará (Ppcclis/UECE); bolsista da Fundação Cearense de Apoio ao Desenvolvimento Científico e Tecnológico (Funcap). E-mail: pauladany85@yahoo.com.br.
} 
subject. In this study it is concluded that by examining the issue of worker's psychic suffering from a psychoanalytical point of view, we can go beyond the approach of the complaint on the medical model of health care, linking this suffering to the psychic series that mark the structuring of this subject.

Keywords: Psychic suffering. Psychoanalysis. Worker health.

\section{Resumen}

Nuestro objetivo es, con base en un caso clínico, ejemplificar cómo la escucha de una queja relacionada con el trabajo puede ser recibida en vista a la singularidad del sujeto y reflexionar sobre la contribución de esta escucha con la atención a la salud del trabajador. Se trata de una encuesta desarrollada por el método de estudio de caso en psicoanálisis. Se discutió cómo la queja relacionada con el trabajo puede ser abordada desde la singularidad del sujeto. En el estudio se concluye que, mediante el estudio de la cuestión del sufrimiento psíquico del trabajador bajo el punto de vista psicoanalítico, se puede ir más allá del abordaje de la queja basándonos en el modelo médico de atención a la salud, vinculando este sufrimiento a las series psíquicas que marcan la estructuración de este sujeto.

Palabras clave: Sufrimiento psíquico. Psicoanálisis. Salud del trabajador.

\section{A clínica e o sofrimento psíquico do trabalhador}

sofrimento humano recebeu diferentes significações ao longo da história. Seja como castigo dos deuses na Grécia antiga, seja como consequência do pecado judaico-cristão (passando pela bruxaria medieval), o sofrimento sempre exigiu do homem uma explicação. $\mathrm{Na}$ sua origem, a palavra "sofrimento" deriva do grego pathos, apontando para aquilo que afeta o homem. Como afirmam Resende \& Castelo Branco Filho (2004, p. 93), pathos "está ligado ao modo afetivo que cada indivíduo constrói para estar no mundo, dizendo respeito não somente às questões de desequilíbrio, mas estando presente também no dia a dia do sujeito e de sua cultura".

A partir do século XVIII, com o nascimento da Medicina moderna, a dimensão do pathos/sofrimento passa a ser paulatinamente tomada nos moldes de uma ciência empírica. Ocorre que, como ciência, a Medicina precisa 
definir seu objeto, reduzindo a complexidade da experiência do sofrimento a algo que possa se submeter às condiçóes de regularidade, previsibilidade e generalização exigidas. Sendo assim, é a redução da doença ao corpo do doente, encontrando nele sua localização anatômica, que vai permitir à Medicina adequar-se aos critérios de cientificidade.

Como consequência imediata desse reducionismo, temos a expulsão no âmbito terapêutico de tudo aquilo que diz respeito à dimensão subjetiva do sofrimento. Como afirma Simanke (2002, p. 22):

O indivíduo como objeto da ciência médica se constitui graças à expulsão de tudo que faz parte da dimensão subjetiva do paciente: a doença é, então, identificada com um processo real de alteração dos tecidos que o método anatomoclínico trata de desvendar com seu olhar: a fala do paciente, queixa subjetiva e desencaminhadora, é preterida em benefício do silêncio do cadáver.

A psiquiatria nasce nesse contexto como a disciplina que deveria ocuparse do sofrimento na sua vertente psíquica, alçada desde então à categoria de "doença mental". De acordo com Simanke (2002), essa definição de "doença mental" como objeto fundante da psiquiatria lança-a imediatamente numa espécie de dilema: só existe doença para aquilo que é localizável no corpo, e a mente é, no entanto, exatamente o que não pode ter apreensão orgânica. Das saídas encontradas para esse dilema, podemos afirmar que a psiquiatria optou por lançar mão de uma explicação pela via da causalidade orgânica, de modo a justificar as alterações patológicas do aparelho mental, na tentativa de "decompor" o sofrimento psíquico em seus elementos de base para, a partir daí, compreendê-los, classificá-los, estudá-los e tratá-los.

Essa forma de pensar o sofrimento como fenômeno orgânico (ou dele derivado) também vai perpassar o campo histórico do trabalho e da sua relação com a saúde mental dos trabalhadores. Conforme aponta Dejours (1992), as doenças do trabalho somente eram reconhecidas quando manifestavam sintomas evidentes no corpo, a tal ponto que não pudessem ser negadas. Assim, os quadros relativos ao sofrimento psíquico sem base orgânica eram desconsiderados e até mesmo "proibidos" de se manifestarem no ambiente de trabalho.

$\mathrm{Na}$ atualidade, percebemos que a negação do sofrimento psíquico no mundo do trabalho ainda é bastante evidente. As intervençōes têm, frequentemente, o objetivo de maquilar o sofrimento e as questôes psíquicas, ou bem são desconsideradas, ou são encaixadas em uma lógica estritamente medicalizante (Brant \& Minayo-Gomez, 2007). 
A psicanálise surgiu no início do século XX como um campo do saber que daria um novo estatuto ao sintoma. Ele deixou de ser um fenômeno a ser lido na superfície do corpo e passou a ser tomado como uma mensagem a ser decifrada.

Embora possa se manifestar como signo corporal, o sintoma caracteriza-se por ser uma formação de compromisso que procura responder a um conflito inconsciente. Além disso, ele exerce um papel na própria organização do sujeito, representando-o enquanto porta-voz de seu desejo (Freud, 1996b).

A contribuição de uma leitura psicanalítica para o campo da saúde do trabalhador está, portanto, em nos permitir abordar as diversas formações sintomáticas sem base orgânica que perpassam esse campo com base em uma lógica da singularidade de cada sujeito, considerando os significantes que marcam a história de vida de cada trabalhador.

Este estudo objetiva exemplificar, com base nem um caso clínico, como a escuta de uma queixa relacionada ao trabalho pode ser apreendida em um serviço de saúde sob uma perspectiva que considere a singularidade do sujeito. Ressaltamos que discutir a dimensão singular do caso não elimina a discussão da inserção do trabalhador em um contexto social e na luta de classes inerentes ao processo de trabalho. Pelo contrário, trata-se de mostrar como, baseado na linguagem, cada sujeito vem a se situar nesse lugar que é, ao mesmo tempo, social e subjetivo.

\section{A clínica psicanalítica e o sofrimento psíquico do trabalhador}

A clínica do sujeito pautada no referencial da psicanálise busca, nas palavras de Erlich (2007), colocar o acento no sujeito do inconsciente, supondo que este é capaz de transmitir um saber desconhecido por outros discursos. Como afirma Lacan (1998, p. 124), o inconsciente é o capítulo da história do sujeito que é marcado por um branco, ocupado por um vazio sem sentido, cujas palavras são incapazes de descrevê-lo ou, por outro lado, constituído por uma mentira: é o capítulo censurado, mas que, ao mesmo tempo, porta consigo um saber.

É por isso que o sintoma não deve ser visto como algo a ser "eliminado". Ele deve, antes, ser "interrogado" na perspectiva de que se possa decifrar algo dessa resposta constituída pelo sujeito. Não significa que o sujeito também não sofra com esse seu sintoma. No entanto, por meio da fala, da articulação dos significantes, pode-se desfazer o sintoma, pois o 
sujeito poderá simbolizar essas coisas inomináveis e buscar uma saída para elaborar seu conflito interno (Furtado, 2005).

A subjetividade excluída do discurso médico é privilegiada no discurso psicanalítico, permitindo compreendermos a possibilidade de articulação entre o sintoma e o modo como cada sujeito investe libidinalmente sua relação com o outro social, incluindo seu modo de amar, de se relacionar com os outros e de trabalhar. Para Bertão \& Hashimoto (2006, p. 142), sujeito é todo aquele que "entra em contato com o mundo, registra suas experiências emocionais e afetivas vivenciadas desde o nascimento, ao longo de sua existência”. Assim, o trabalho desponta nas articulações significantes de um dado sujeito como mais um dos elementos que perpassam suas séries psíquicas e que só adquire seu sentido se conectada a outros elementos de sua história.

Compreendemos, a partir da clínica psicanalítica, que todas as experiências do sujeito vão ser significadas a partir do lugar que esse sujeito ocupa em relação à linguagem. Assim, o sofrimento psíquico do trabalhador não pode ser pensado apenas como fator inerente aos estímulos externos (organização do trabalho, infraestrutura, ritmo de produção), mas precisa ser abordado a partir de como essa relação com o trabalho se insere na economia psíquica de cada um. O sofrimento depende da significação que assume no tempo e no espaço, bem como no corpo que ele toca, produzindo algo que está "além do princípio do prazer".

O corpo do ser falante diferencia-se das demais formas de vida por ser afetado pela linguagem. Não lidamos com o mundo objetivo, mas com representações que já são construídas de forma singular, a partir das experiências que constituem o sujeito. É em decorrência dessa exigência da linguagem que entra em jogo "algo mais" que se inscreve no corpo. No campo da saúde do trabalhador, esse "algo mais" que insiste em se manifestar muitas vezes é apreendido como doença mental e, portanto, passível de intervenção médica.

A psicanálise subverte a anatomia e instaura-se outra rede de demarcações. O corpo é marcado pela palavra, constituindo-se como corpo libidinal. Em vez de ser guiado por instintos (como acontece com o animal preso à imediaticidade do natural), entra em jogo algo que é da dimensão da "pulsão". Essa concepção foi criada por Sigmund Freud (1996d, p. 57) como conceitolimite entre o psíquico e o somático, "o representante psíquico dos estímulos que provêm do interior do corpo e alcançam a psique, como uma medida da exigência de trabalho imposta ao psíquico em consequência de sua relação com o corpo". 
A entrada na civilização, o recurso à linguagem, exige que uma parcela dessa satisfação pulsional seja deixada de fora. Apesar de toda essa tentativa de controle dos corpos, a pulsão continua exigindo outro trabalho, buscando formas de se manifestar.

$\mathrm{Na}$ neurose, o caminho encontrado para obter a satisfação é o sintoma. Trata-se de uma satisfação também paradoxal, pois, como afirma Freud (1996d), embora seja sentida pelo sujeito como sofrimento, denota que, em outra cena, algo da pulsão consegue se satisfazer parcialmente. Para a psicanálise, o sintoma é sintoma de algo, está no lugar de algo que não pôde ser dito, não encontrou possibilidade de ser representado em palavras e, por isso, busca outras possibilidades de representação. Esse "algo" impossível de ser dito não diz respeito apenas a um acontecimento atual (uma situação de estresse no trabalho, por exemplo). Ele remete a um real traumático que está na base da própria constituição do sujeito.

Assim, para além de uma afecção biofisiológica, o sintoma para a psicanálise é um significado, uma resposta do sujeito diante do encontro com o real traumático. Trata-se de uma resposta que carreia um desejo, embora se trate de um desejo inconcebível (Quinet, 2006). Estamos aí diante de outra face do sintoma apresentada por Freud, aquela que envolve uma forma paradoxal de satisfação do desejo, uma satisfação que não pode ser reconhecida como tal pela consciência (Freud, 1996b).

A posição da consciência diante do saber inconsciente é a de "não querer saber nada disso", a qual é reforçada no modelo médico-científico, no qual o sujeito é desresponsabilizado por seu sintoma. A psicanálise considera que esse saber se revela na fala daquele que vem se queixar, desde que ela encontre do outro lado um analista. É nos sonhos, nos lapsos do discurso, nas distorções, nas lacunas e nas repetiçôes do sujeito, assim como em seus sintomas, que se lerá o traço apagado do significante recalcado, emergente na linguagem singular, na fala de cada sujeito que apreende o desejo inconsciente. Esse desejo abriga inadvertidamente um sentido, determinando a maneira pela qual cada sujeito pode se haver com seu desejo (Lacan, 1999).

\section{Metodologia}

O trabalho pauta-se em um estudo desenvolvido por meio do método de estudo de caso em psicanálise. Segundo Viganò (1999), trata-se de um método que tem a finalidade de fazer o sujeito falar, trazendo para a cena discursiva aquele que sofre, reconhecendo que seu sofrimento se articula ao modo como sua estrutura psíquica se organizou. 
Para operacionalizar nosso estudo, optamos pelo "método de estudo de caso em psicanálise”, conforme proposto por Guimarães \& Bento (2008). O método é composto por três etapas: escrita do "pathos-doença", escrita do "pathos-transferência" e escrita da construção teórica.

A escrita do "pathos-doença" se inicia com o registro dos dados anamnésicos necessários para compor a queixa do paciente, articulando os aspectos da evolução da doença, desde seu aparecimento até suas manifestaçôes atuais, com os acontecimentos da história de vida do paciente. A segunda etapa reporta-se à escrita do "pathos-transferência", na qual se dá o estabelecimento da relação transferencial analista-sujeito centrada na promoção de uma retificação subjetiva, estimulando o sujeito a aplicar-se naquilo que se constitui como objeto de sua queixa. Por último, destacase a escrita da construção teórica. Nesse momento, trata-se de escrever a análise e a interpretação das histórias da doença e da transferência do sujeito, objetivando realizar uma discussão clínica, analisando e interpretando os dados descritivos do "pathos-doença" e do "pathos-transferência" para aceder ao nível da construção teórica em psicanálise.

O estudo de caso foi desenvolvido com base no atendimento clínico individual em uma unidade básica de saúde do Município de Fortaleza-CE. A escuta clínica é ofertada nessa unidade de saúde por meio do projeto de extensão "Psicanálise e Clínica Social", coordenado por uma das autoras.

Esse projeto surgiu de uma crítica à perspectiva de "clínica" que permeia o modelo atual de atenção à saúde. Trata-se de uma clínica desenvolvida sob a égide do saber médico, pautada no crescente incentivo à especialização do saber; este que permanece do lado do profissional e nunca do sujeito que vem se queixar. Além disso, sob esse viés, recorre-se cada vez mais à proposta de uma "clínica baseada em evidências", na tentativa de mapear neurologicamente as emoções humanas para classificá-las e padronizá-las em sistemas de diagnóstico "ateóricos" como vem sendo a proposta do sistema de Classificação Internacional de Doenças (CID). Por fim, a intervenção operada nessa clínica pauta-se quase que exclusivamente na oferta de medicações que supostamente seriam capazes de aplacar o sofrimento.

O projeto de extensão referido pauta-se no discurso psicanalítico para se posicionar na contramão dessa clínica baseada no modelo médico, situando o saber do lado do sujeito do inconsciente, considerando o sintoma como manifestação desse sujeito que é convocado a falar sobre si. $\mathrm{O}$ caso que aqui relatamos foi oriundo de um atendimento desenvolvido durante um período de cinco anos, em sessóes individuais semanais. $\mathrm{O}$ trabalho foi submetido ao 
Comitê de Ética em Pesquisa da Universidade Estadual do Ceará, atendendo à resolução 196/96, com o parecer de aprovação 10340285-3.

\section{Caso Marcélia}

\subsection{A escrita do "pathos-doença" e a descrição da história da doença}

Marcélia, 39 anos, procurou atendimento no serviço público de saúde e foi encaminhada pelo médico da equipe para atendimento clínico no projeto de extensão "Psicanálise e Clínica social". Esse encaminhamento era oferecido sempre que, na consulta médica, fosse identificada uma queixa de sofrimento psíquico. A queixa que a levou ao serviço era de ansiedade e insônia. Sentiase deprimida e disse que fazia uso de paroxetina e clonazepam, conforme prescrição anterior.

Segundo Marcélia, tudo começou em 2005, quando sofreu um "assédio moral" por parte de seu patrão. Trabalhava havia quatro anos, como caixa numa loja de shopping e começou a apresentar uma dor nos braços que foi diagnosticada como tendinite em decorrência do trabalho repetitivo. Ao receber o diagnóstico, Marcélia procurou o patrão, que sugeriu que ela pedisse demissão. Como se recusou, o patrão começou a fazê-la passar por situações constrangedoras, como sentar numa cadeira isolada e passar o dia sem falar com ninguém. A partir daí, ela resolveu processá-lo.

Sua inquietação e seu sofrimento derivaram do fato de que as pessoas não acreditavam em sua doença. $\mathrm{O}$ patrão passou a desmenti-la nas audiências; os médicos não encontraram uma lesão demonstrável, e isso a incomodou: "Queria encontrar um exame que mostrasse que o que sinto é real".

Diante das audiências, ficou terrivelmente angustiada. Temeu que o patrão conseguisse ganhar a causa e que, assim, pudesse provar que ela não tinha uma doença. Foi por isso que resolveu buscar atendimento em busca de uma "palavra de médico".

\subsection{A escrita do "pathos-transferência"}

Marcélia é a mais nova de uma família de sete filhos, sendo quatro mulheres e três homens. O pai trabalhava viajando e frequentemente tinha que se mudar de cidade. A mãe acompanhava o marido nessas mudanças, levando consigo todos os filhos. O pai é relatado como "um pai paterno", muito carinhoso. Ele ficava pouco tempo em casa, mas, na hora do almoço, fazia questão de que os filhos menores comessem no mesmo prato que ele. A mãe, por sua vez, era quem sempre tinha a última palavra: "Era ela quem comandava". 
Aos 12 anos, descobriu que o pai tinha outra mulher. Ao relatar a história, cometeu um lapso e disse: "Minha mãe arrumou outra". Virgem aos 39 anos, disse que nunca se havia interessado muito pelos homens e "nem pelas mulheres!". Lembrou-se de que, no início da adolescência, lia, escondida, um livro sobre sexualidade. Culpou a mãe por não lhe ter ensinado nada sobre esses assuntos. Até já pensara em encontrar alguém que a respeitasse, que fosse carinhoso, mas desistiu, pois não queria sofrer como via acontecer com a irmã e a cunhada que sofriam por causa dos maridos. Enfim, perdeu esse tipo de interesse, e o trabalho passou a ser mais importante em sua vida.

Numa determinada sessão, Marcélia chegou chateada porque uma colega a chamara de autoritária:

Eu não sou autoritária, mas minha voz sai assim. Na verdade, eu quero é ajudar as pessoas. Como eu aprendi muito sobre os direitos das pessoas, eu gosto de orientar, dar conselhos. Mas elas acham que eu estou sendo autoritária, querendo mandar.

A analista fez uma intervenção, no sentido de apontar que nem sempre as pessoas queriam ser aconselhadas. Ela disse: "Pois é, poucos querem saber". Diante dessa constatação, a analista perguntou: "E você, o que é que você quer?”. Essa intervenção produziu o efeito de uma implicação subjetiva em Marcélia. Ela deslocou sua queixa relacionada a uma suposta lesão no corpo e começou a se perguntar sobre a influência, no seu sintoma, das coisas que vivera no passado: não se sentir cuidada, ter que se virar sozinha e, principalmente, ser comandada pela mãe que, segundo ela, estava sempre exigindo que ela trabalhasse em casa, nos afazeres domésticos, de forma rápida e eficiente, não admitindo erros.

Marcélia, que inicialmente viera procurar uma "palavra de médico", percebeu que a analista não atendia a essa demanda e começou a procurar, na sua própria história, as respostas para seu enigma. Ela passou a falar sobre aquela voz que soava grosseira, autoritária, mas que ela não "comandava". Algo falava nessa voz mais do que ela pensava dizer. Passou a perceber que a única pessoa com quem ela não se portava assim era com a irmã: "Faço tudo pra ela não se chatear". A analista apontou a similaridade com o patrão, a quem ela também se esforçava para agradar. Ela disse:

Pois é. Eu fiz de tudo pra agradar a ele, me esforcei muito e passei a trabalhar mais ainda, pra ele não ter o que dizer. Era sempre a última a sair, ficava até tarde limpando o chão. Mas, por mais que eu fizesse, ele não reconhecia. Eu sempre fazia um "a mais" pra que ele reconhecesse. 
A analista pontuou algo no sentido da relação disso com o adoecimento. Ela se surpreendeu e disse: "Será que foi por isso que eu adoeci?".

Marcélia, sem ainda saber, falava daquele "a mais" que se condensava em seu corpo. A analista perguntou por que ela se preocupava tanto em agradar ao patrão, à irmã, e ela disse: "Eu fazia isso pra mostrar que eu não era uma inútil, que eu tinha valor".

Ao longo do tratamento, Marcélia foi se deparando com o fato de que se afastara dos homens por medo de repetir nos seus relacionamentos aquilo que ela considerava ser a lógica do relacionamento de seus pais: "Eu acho que eu fiquei com um medo. Medo de errar ou perder. Porque eu acho que numa relação é o homem que tem que comandar, e eu tenho medo que ele não comande. Porque, com a minha mãe, era assim, era ela quem comandava”.

\subsection{Articulação teórica}

A queixa inicial de Marcélia ao procurar o serviço de saúde era por sentir-se deprimida, referindo ainda os sintomas de "ansiedade e insônia". Submetida ao discurso médico, Marcélia tentou situar sua queixa no real do corpo. Afirmou querer encontrar um exame que provasse a verdade do que ela sentia. A dor e o sofrimento constituíam-se, para Marcélia, em inúmeras situaçôes: na perda da saúde, na decepção ao ser isolada no ambiente de trabalho, pelo não reconhecimento das suas habilidades laborais, na humilhação no expediente de trabalho e no lócus das audiências. Ela sofria por precisar provar aquilo que lhe afligia e que, portanto, era "real".

$\mathrm{Na}$ clínica psicanalítica, essa queixa inicial trazida não era a questão central a ser analisada. Era a inserção de Marcélia em análise que lhe proporcionaria passar por uma reformulação, e implicar-se-ia, de alguma forma, naquilo de que vinha se queixar.

Assim, fez-se necessário perceber o sintoma não como significado natural da doença patológica. O sintoma é um enigma a ser decifrado, que se dirige ao Outro, e que porta a marca de uma satisfação substitutiva, apontando para a relação do sujeito com a castração (Freud, 1996b). No entanto, transformar a queixa inicial em um enigma só vai ser possível pela instauração da transferência. Ao dirigir sua queixa à analista, Marcélia passou a supor nesta um saber sobre o que a afligia, esperando dela "uma palavra de médico". Essa palavra que ela esperava se situava na série das palavras de comando, na mesma em que estavam incluídas a mãe, a irmã mais velha e o patrão.

A transferência é conceituada por Freud (1996a) como reedições das fantasias infantis que, durante a análise, vão se atualizar na pessoa do analista. 
Daí Freud dizer que, na transferência, o analista é colocado no lugar de uma das imagos primordiais do indivíduo: imago paterna, imago fraterna ou imago materna (Freud, 1996a). Muito tempo depois, Lacan (1992) traria sua contribuição para essa discussão, ao afirmar que se tratava aí de uma relação de amor, mas um amor ao saber. $\mathrm{O}$ sujeito coloca-se na posição daquele que não sabe e situa o analista no lugar de quem tem o saber, lugar de alguém que vem tamponar a sua falta. É um significante qualquer do analista que vem engatar a transferência para o sujeito.

No caso de Marcélia, vemos que é o significante "palavra de médico" que vem fazer essa função. Ao não atender a essa demanda e ao colocar o sujeito frente ao enigma do seu desejo ("E você, o que você quer quando aconselha essas mulheres?”), o analista permitiria o surgimento do desejo como questão, apontando para o outro lugar onde ele se situava: o desejo do Outro. Dessa forma, Marcélia passou a perceber sua implicação naquilo de que vinha se queixar, e o sintoma adquiriu o estatuto de uma pergunta: "Será que foi por isso que eu adoeci?"”.

A pergunta de Marcélia em relação ao desejo do Outro apontou para a busca de uma resposta que nomeasse seu ser. Trata-se do mecanismo pelo qual a histérica constitui-se em sua relação com o desejo. $\mathrm{O}$ sujeito histérico é aquele que demonstra a busca do ser. Ele sofre, tem um forte sentimento de ser um vazio, de ser nada (Soler, 2005). No caso de Marcélia, vemos que a busca por essa "palavra de médico" era uma forma de ela tentar tamponar seu vazio.

Em termos simbólicos, na resposta que construía frente ao desejo do Outro, a mulher apareceu como aquela que comandava (na referência à sua mãe, na sua voz que soa de maneira autoritária ou, ainda, na "palavra de médico" que ela esperava da analista). O pai, em vez de fazer a função de comando, barrando a mãe, apareceu despotencializado, enquanto Marcélia esperava dele uma potência. Com seu sintoma, ela fez ressurgir esse pai potente na figura do patrão que Marcélia interpretava como exigindo dela um "a mais".

Sabemos que é impossível para o sujeito representar tudo na linguagem e que esse "a mais" que Marcélia esperava está no plano daquilo que escapa à possibilidade de representação, do impossível, portanto. Quando isso se torna presente, diz-se que o sujeito se encontra no plano do traumático, da angústia. Para Marcélia, isso ocorria quando ela supunha que o "a mais" que o patrão buscava estava voltado também para outras mulheres: as colegas de trabalho que saíam com ele para beber, sentavam em seu colo e o acompanhavam em festas. Ela, que pensou poder atender àquele "a mais", esforçando-se no 
trabalho, ficando até mais tarde, limpando o chão, etc., percebeu que ele não se interessava por ela, ao contrário, reclamava de seu trabalho e até acusava-a de desviar dinheiro. O patrão agia assim como seu pai, que saíra da cena familiar em busca de satisfação com outras mulheres, deixando-a entregue aos caprichos da mãe que comandava.

O sintoma de Marcélia também portava uma face de satisfação, algo que ali se repetia, buscando se satisfizer. Tornou-se presente também o cerne da questão histérica que implicava, por um lado, a dificuldade de se colocar como mulher. Marcélia negava os relacionamentos com os homens e se mantinha virgem aos 39 anos de idade. Recusava-se a se relacionar por medo de que esse homem não "a comandasse".

Colocar-se como objeto de desejo na fantasia de um homem lhe era difícil. Marcélia se furtava a esse lugar de objeto, não tolerava a posição feminina. $\mathrm{O}$ que era ser uma mulher? A mulher buscava, pelo olhar de um homem, da relação com a mãe e com as outras mulheres, a chave do enigma. Em suas queixas, encontravam-se sentimentos de inferioridade e de injustiça. A necessidade de ser amada aparecia como consequência de seu sofrimento (Soler, 2005). Diante desse enigma, a mulher histérica procura um mestre que queira saber sobre seu mistério, mas acaba por castrar o mestre de seu saber, mostrando ser ele impotente para dar conta dela.

Freud desenvolveu, mais tarde, em seu texto Feminilidade (1996c), que a mulher com dificuldade de separar-se da mãe pode apresentar dificuldades para abraçar uma relação com um homem. Surge o ressentimento e a culpabilidade direcionados à mãe. Soler (2005) nos coloca que isso ocorre porque um sujeito histérico se posiciona no nível da separação, no medo de perder o ser amado, ou seja, no nível do questionamento do desejo do Outro. A angústia do sujeito histérico talvez se deva ao fato de ele duvidar que haja lugar para ele no Outro. É por isso que ele tenta sempre tornar o Outro incompleto, e consequentemente, sempre insatisfeito.

Diante do dilema edípico no qual a menina se vê lançada, ela espera que o pai possa responder pelo que quer a mãe (Lacan, 1999). No caso de Marcélia, no entanto, vemos como esse pai, que deveria ser o detentor do falo, aquele a quem a mãe deveria se dirigir com seu desejo, aparece como um "pai paterno" e, principalmente, comandado pela mãe. Essa despotencialização do pai a deixa mais uma vez submetida aos caprichos de uma mãe que comanda, e deseja que ela trabalhe incansavelmente. $\mathrm{O}$ sintoma surge, portanto, como forma de barrar essa imposição materna 
(as dores a impedem de trabalhar), ao mesmo tempo em que, ao impedi-la de trabalhar, coloca-a novamente em uma situação de dependência dessa mãe.

\section{Considerações finais}

$\mathrm{Na}$ literatura médica, o fenômeno que acomete Marcélia é descrito como LER (lesão por esforço repetitivo) ou mais recentemente como DORT (doença osteomuscular relacionada ao trabalho). Gostaríamos de finalizar este texto com uma observação acerca dessa mudança na nomenclatura. Chamanos a atenção o fato de que, na nova denominação, o significante "lesão" desaparece. Entendemos que a exclusão desse termo expressa uma inquietação dos pesquisadores da área quanto à prevalência de aspectos subjetivos em detrimento de uma alteração orgânica.

O caso aqui apresentado é paradigmático para pensarmos as consequências de um diagnóstico relacionado ao trabalho que não pode ser objetivado em uma lesão. Sob o olhar médico-jurídico, Marcélia padecia por não conseguir comprovar que seu sofrimento era real e, assim como as histéricas da época vitoriana, era tratada como alguém que "fingia". O processo que enfrentou na Justiça contra o patrão foi perdido porque o laudo pericial não apontou elementos suficientes para comprovar a existência da doença e muito menos um nexo causal com o trabalho.

A escuta numa perspectiva psicanalítica desses sujeitos abre espaço para outras possibilidades de lidar com o sintoma, já que o que vai estar em jogo não é a verdade científica, mas a verdade que cada um pode produzir acerca daquilo que o assola. Assim, cada um traz no bojo de seu discurso um saber inconsciente, um saber não sabido, mas que, ao ser colocado em funcionamento, tem efeitos importantes para uma mudança de posição subjetiva.

Certamente não se trata aqui de propor a escuta psicanalítica como um modelo de intervenção na atenção à saúde do trabalhador. Isso não seria desejável nem mesmo possível, já que a psicanálise envolve um processo de implicação quase artesanal, tanto do lado de quem escuta (que só pode ocupar esse lugar a partir de sua própria análise) como do lado de quem aceita transformar sua demanda de resposta dirigida ao outro em uma pergunta que implique o seu próprio saber inconsciente. No entanto, apostamos que a sustentação de uma escuta psicanalítica no serviço de saúde pode permitir a alguns sujeitos um espaço singular de elaboração de sua dor. Esperamos que o caso aqui abordado possa instigar outras reflexões acerca dessas possibilidades. 


\section{Referências}

Bertão, F. R. B. M., \& Hashimoto, F. (2006). Entre o desejo e o sofrimento psíquico no trabalho: um estudo de caso com professora de educação infantil. Psicologia em Revista, 12 (20). Recuperado em 15 abril, 2014, de http://periodicos.pucminas.br/index.php/psicologiaemrevista/article/ view/249/259.

Brant, L. C. B., \& Minayo-Gomez, C. (2007). Dispositivos de transformação do sofrimento em adoecimento numa empresa. Psicologia em Estudo, 12 (3), 465-473.

Dejours, C. (1992). A loucura do trabalho: estudo de psicopatologia do trabalho. São Paulo: Cortez.

Erlich, H. (2007). Psicanálise e ciência: um sujeito, dois discursos. Dissertação de Mestrado, Universidade do Estado do Rio de Janeiro, Rio de Janeiro, RJ, Brasil.

Freud, S. (1996a). A dinâmica da transferência. In S. Freud. Edição standard brasileira das obras completas de Sigmund Freud (J. Salomão, Trad., Vol. 22, pp. 131-143). Rio de Janeiro: Imago. (Obra original publicada em 1912).

Freud, S. (1996b). Conferência XXIII: Os caminhos da formação dos sintomas. In S. Freud. Edição standard brasileira das obras completas de Sigmund Freud (J. Salomão, Trad., Vol. 26, pp. 397-417). Rio de Janeiro: Imago. (Obra original publicada em 1976).

Freud, S. (1996c). Conferência XXXIII: Feminilidade. In S. Freud. Edição standard brasileira das obras completas de Sigmund Freud (J. Salomão, Trad., Vol. 22, pp. 139-165). Rio de Janeiro: Imago. (Obra original publicado em 1933).

Freud, S. (1996d). Os instintos e suas vicissitudes. In S.Freud. Edição standard brasileira das obras completas de Sigmund Freud (J. Salomão, Trad., Vol. 14, pp. 129-162). Rio de Janeiro: Imago. (Obra original publicada em 1915-1916).

Furtado, L. A. R. (2005). Pela via do sintoma: da atividade laboral ao trabalho psíquico. Dissertação de Mestrado, Universidade Federal do Ceará, Fortaleza, CE, Brasil.

Guimarães, R. M., \& Bento, V. E. S. (2008). O método do "estudo de caso" em psicanálise. Revista Psicologia, 39 (1), 91-99. 
Lacan, J. (1992). O Seminário, livro 8: a transferência. Rio de Janeiro: Jorge Zahar. (Obra original publicada em 1960-1961).

Lacan, J. (1998). Função e campo da fala e da linguagem em psicanálise. In J. Lacan. Escritos. (pp. 238-324). São Paulo: Perspectiva. (Obra original publicada em 1978).

Lacan, J. (1999). O Seminário, livro 5: as formaçôes do inconsciente. Rio de Janeiro: Jorge Zahar. (Obra original publicada em 1957-1958).

Quinet, A. (2006). A descoberta do inconsciente: do desejo ao sintoma. Rio de Janeiro: Jorge Zahar.

Resende, T. I. M. de, \& Castelo Branco Filho, J. C. (2004, janeiro-julho). A patologia como possibilidade estruturante do sujeito: uma releitura da questão prática. Universitas: Ciência da Saúde, 2 (1), 1-151. Recuperado em 15 fevereiro, 2011, de http://www.publicacoesacademicas.uniceub.br/index. $\mathrm{php} /$ cienciasaude /article/viewFile/525/346.

Simanke, R. T. (2002). Metapsicologia lacaniana: os anos de formação. São Paulo: Discurso.

Soler, C. (2005). O que Lacan dizia das mulheres. Rio de Janeiro: Jorge Zahar.

Viganò, C. (1999, Setembro). A construção do caso clínico em saúde mental. Revista Curinga: Psicanálise e Saúde Mental, 13, 55-59. 